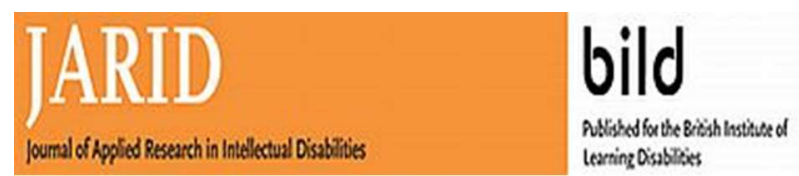

\title{
The Clinical, Forensic, and Treatment Outcome factors of patients with Autism Spectrum Disorder treated in a Forensic Intellectual Disability Service
}

\begin{tabular}{|c|l|}
\hline Journal: & Journal of Applied Research in Intellectual Disabilities \\
\hline Manuscript ID: & JARID-11-2013-OA-0149.R2 \\
\hline Weywords: & $\begin{array}{l}\text { Intellectual Disability, Learning Disability, Autistic Spectrum Disorder, } \\
\text { Forensic, Comorbidity, Treatment Outcomes }\end{array}$ \\
\hline & $\begin{array}{l}\text { Background: To describe the characteristics of those with autism spectrum } \\
\text { disorder (ASD) treated within a forensic intellectual disability hospital and } \\
\text { to compare them with those without ASD. }\end{array}$ \\
& $\begin{array}{l}\text { Method: Service evaluation of a cohort of } 138 \text { patients treated over a } 6 \\
\text { year period. } \\
\text { Abstract: } \\
\text { Results: Of the 138, 42 had an ASD. Personality disorders and harmful use } \\
\text { or dependence on drugs were significantly lower in the ASD group. The } \\
\text { ASD group was less likely to be subject to criminal sections or restriction } \\
\text { orders. Self-harm was significantly higher in the ASD group. There were no } \\
\text { differences in the length of stay and direction of care pathway. } \\
\text { Conclusions: Although the ASD and non-ASD groups differ on clinical and } \\
\text { forensic characteristics, their treatment outcomes appear similar. This } \\
\text { suggests that the diagnostic category of ASD alone may be inadequate in } \\
\text { predicting the treatment outcome. There is a case to identify distinct } \\
\text { typologies within the ASD group. }\end{array}$ \\
\hline
\end{tabular}




\title{
The Clinical, Forensic, and Treatment Outcome Factors of Patients with Autism Spectrum Disorder Treated in a Forensic Intellectual Disability Service
}

\begin{abstract}
Background: To describe the characteristics of those with autism spectrum disorder (ASD) treated within a forensic intellectual disability hospital and to compare them with those without ASD.
\end{abstract}

Method: Service evaluation of a cohort of 138 patients treated over a 6 year period.

Results: Of the 138, 42 had an ASD. Personality disorders and harmful use or dependence on drugs were significantly lower in the ASD group. The ASD group was less likely to be subject to criminal sections or restriction orders. Self-harm was significantly higher in the ASD group. There were no differences in the length of stay and direction of care pathway.

Conclusions: Although the ASD and non-ASD groups differ on clinical and forensic characteristics, their treatment outcomes appear similar. This suggests that the diagnostic category of ASD alone may be inadequate in predicting the treatment outcome. There is a case to identify distinct typologies within the ASD group.

\section{Keywords}

1. Intellectual Disability

2. Learning Disability

3. Autistic Spectrum Disorder

4. Forensic

5. Comorbidity

6. Treatment Outcomes 
ASD IN FORENSIC INTELLECTUAL DISABILITY

\section{The Clinical, Forensic, and Treatment Outcome Factors of Patients with Autism Spectrum Disorder Treated in a Forensic Intellectual Disability Service}

\section{Introduction}

Autism spectrum disorder (ASD) is characterised by deficits in social communication and interaction; including social-emotional reciprocity, nonverbal communicative behaviours, and with developing, maintaining, and understanding relationships (American Psychiatric Association, 2013). People with ASD can present with preoccupations, stereotyped behaviours, sensitivities, obsessive-compulsive behaviours, and anxiety (Gunasekaran 2012). The National Autistic Society (2013a) suggests there are approximately 700,000 people in the UK with ASD.

The offending behaviour of those with ASD is subject to a degree of clinical and media interest, evidenced by the volume of case studies describing serious offending behaviour of those with ASD (e.g. Baron-Cohen 1988; Chen et al. 2003; Chesterman \& Rutter 1993; Schwartz-Watts 2005; Cooper et al. 1993; Everall \& Le Couter 1990; Mawson et al. 1985; Milton et al. 2002; Murrie et al., 2002; Silva et al. 2002), and sensationalist media reporting of criminal cases (Howlin 1997; Allen et al. 2008; Gómez de la Cuesta 2010).

The prevalence of offending behaviour by those with ASD is unknown. Studies from forensic settings (e.g. secure hospitals and prisons) suggest ASD is overrepresented, with reported rates between $1.5 \%$ to $30 \%$ (Scragg \& Shah 1994; Alexander et al. 2011). However, studies have been limited by methodological issues including single service samples, selected populations and lacking cohesiveness in the definition and assessment of ASD (Gómez de la Cuesta 2010). Further, those with ASD experience disadvantage when interacting with criminal justice agencies, particularly police interviews (Archer \& Hurley 2013; North et al. 2008). Those with 
ASD IN FORENSIC INTELLECTUAL DISABILITY

adequate language skills may not appear vulnerable, meaning that police and courts fail to provide support to assist with communication and protect the individual's rights. Archer and Hurley (2013) note that defendants with ASD often present with a lack of empathy / remorse and so may be more harshly sentenced.

Regardless of exact prevalence rates, there are significant numbers of people with autism spectrum disorder within criminal justice settings. Despite the high level of clinical interest in this group, research focusing on sociodemographic, clinical and forensic characteristics, and treatment outcomes is scarce. In terms of sociodemographic factors, it has been suggested that the majority of offenders with ASD are male (Dein \& Woodbury-Smith 2010), though notably Crocombe and colleagues (2006) found roughly $10 \%$ of women in a high secure unit met ICD-10 criteria for ASD. Regarding comorbidity, Woodbury-Smith (2005) reported that $19 \%$ of an offender group with Asperger syndrome met antisocial personality disorder criteria. Woodbury-Smith (2008) reported increased prevalence of anxiety, depression, sleep problems and other developmental disorders (e.g. Tourette syndrome, attention-deficit hyperactivity disorder). Studies also suggest offenders with ASD have different forensic profiles to other offender groups. Murphy (2003) reported no high secure hospital patients with Asperger syndrome had any history of serious antisocial behaviour or criminal convictions before age 18 .

Murphy (2010) suggested that issues with behavioural and social interactions mean this group can present clinical challenges and be difficult to engage therapeutically within forensic services. Traditional markers of therapeutic progress used within forensic services, such as stable behaviour, may not evidence the same progress in those with ASD (Dein \& Woodbury-Smith, 2010). Wing (1997) notes that 


\section{ASD IN FORENSIC INTELLECTUAL DISABILITY}

patients with ASD may behave in an exemplary manner in a particular environment, but reoffend if transferred to an inappropriate or unfamiliar setting.

Haw et al. (2013) examined the characteristics of 51 male forensic patients with ASD in low secure care, comparing them to 43 patients without ASD. The authors reported numerous significant differences between the groups. Those with ASD were younger (27 vs. 33 years) and younger at their first contact with psychiatric services. Almost $75 \%$ of those with ASD had psychiatric comorbidity, most commonly schizophrenia; and 4.4\% had personality disorders. Drug and alcohol disorders were uncommon, though many had histories of misuse. Those with ASD were more likely to be admitted from prison or courts. Over $75 \%$ had a history of physical violence and a third convictions for serious violence or homicide. Offending behaviour was described as atypical, involving uncommon offences, e.g. harassment or stalking.

ASD is prevalent in forensic intellectual disability populations, with reported rates ranging from $15.8 \%$ (Alexander et al. 2006) to 30.44\% (Alexander et al. 2010; 2011). However, research examining the clinical comorbidities, forensic histories and treatment outcomes of those with ASD in forensic intellectual disability populations is scarce. This paper aims to further investigate these areas.

\section{Method}

This study was part of a service evaluation project of a 64 bed specialised forensic inpatient intellectual disability service in England. The service has a nationwide catchment area and accepts referrals from settings such as prisons and other secure services. Findings have been described earlier (e.g. Alexander et al. 2010; 2011). This paper examines the autism spectrum disorder (ASD) group in further detail. All patients treated within the service over a 6-year period were 
included in the study. Retrospective case file data collection was done by three authors (R.A., I.G., S.H.) who treated these patients in their capacity as Consultant Psychiatrists. Patients with autism spectrum disorder (ASD) were identified. The clinical, forensic and treatment outcome profiles of those with ASD were investigated and compared to those without ASD treated over the same period. Definitions of clinical, forensic and treatment outcome variables are as follows:

\section{Clinical variables}

- Age

- Gender

- Diagnosis: The service had an established structure of assessments (Selby \& Alexander, 2004) and used ICD-10 diagnostic criteria (World Health Organization, 1992) to generate a diagnosis for each patient. This covered the degree and cause of ID, autism spectrum disorder, personality disorders, mental illnesses, harmful use or dependence on alcohol or illicit drugs, physical disorders, psychosocial stress factors and behavioural problems. This system captures the extensive comorbidity experienced by offenders with ID.

- Abuse: Evidence of a child protection, or protection of vulnerable adult response by social services had to be documented before abuse was recorded as present.

- Self-harm: Self-harm history recorded as either present or absent.

\section{Forensic variables}

- Legal Status: Patients within the service are detained under the Mental Health Act 1983. Although all had some degree of offending behaviour, not all went through the criminal justice process. Sections $35-38,47$ and 48 of the Mental Health Act, where the detention order is made by a court or Ministry of Justice were designated as 'criminal sections'. The study also recorded 'restriction orders', a 


\section{ASD IN FORENSIC INTELLECTUAL DISABILITY}

Mental Health Act (1983) provision where power to discharge patients is taken from the treating clinician and given to the Mental Health Review Tribunal or Ministry of Justice.

- Conviction history: Three categories of past convictions were recorded; violent (interpersonal physical violence), sexual and arson.

- Aggression history: Five parameters of aggression were recorded as present or absent: verbal, aggression to people, to property, sexual, and fire setting. This aimed to capture those whose behaviour had not been processed by the criminal justice system.

\section{Treatment outcome variables}

For treatment outcomes analysis, the study group was divided into two subgroups; discharged patients, and those not yet discharged.

- Institutional Aggression: Use of seclusion, physical intervention and observation and pro re nata (PRN) medication were used as proxy measures for institutional aggression. Data on these interventions were only available for 114 patients.

- Length of Stay: Mean length of stay was calculated for discharged patients, and those not yet discharged from the service during the study period.

- Direction of Care Pathway and Discharge Placement: A 'good' outcome was defined by the patient being discharged to a lower level of security. A 'poor' outcome was a discharge to the same or higher level of security. For discharged patients, the placement was recorded, e.g. were they discharged to another hospital, or directly to the community; on a guardianship order, supervised discharge, or as an informal patient.

\section{Ethics}


Ethical approval was sought from the Norfolk (1) Research Ethics Committee who advised the project was service development, and did not need to be ethically reviewed under the Governance Arrangements for Research Ethics Committees in the UK.

\section{Statistical analysis}

Data was analysed using SPSS - Version 20. Fishers exact tests were used for comparison of categorical variables and Mann-Whitney U-test for comparison of means.

\section{Results}

Of the 138 patients, $42(30 \%)$ had autism spectrum disorder. The clinical, forensic, and treatment outcome factors of this group were explored, and compared to those without ASD.

\section{Clinical variables}

The clinical factors are described in Table 1.

Insert Table 1: Comparison between those with ASD and those without: Clinical variables

\section{Forensic variables}

Table 2 describes results on forensic histories and offending behaviours.

Insert Table 2: Comparison between those with ASD and those without: Forensic variables

\section{Treatment Outcomes}

Table 3 displays the information on treatment outcomes. 


\section{ASD IN FORENSIC INTELLECTUAL DISABILITY}

Insert Table 3: Comparison between those with ASD and those without: Treatment Outcomes

\section{Discussion}

Despite large numbers of people with autism spectrum disorder being treated within forensic intellectual disability services, there is limited research focusing on them. This study examined the clinical, forensic, and treatment outcome factors associated with this group. The sample is drawn from a single service and hence readers should be cautious about drawing generalisable conclusions. The study used a service evaluation, retrospective methodology, which limited the hypotheses explored within the data. Further, the study did not use standardised instruments or structured assessments to establish the ASD diagnosis. Those of normal or above average intelligence diagnosed with Asperger's may be under-represented in the sample because the study is from a unit for those with an intellectual disability.

However the study does report treatment over a six year period, has one of the largest samples described so far in this area, and is based in a unit which has a structured approach to diagnosis. Further, the clinicians involved were directly involved in the treatment of all patients throughout the period described. Thus, notwithstanding the drawbacks, the study highlights a number of interesting findings, for a patient group about which there is very limited published literature.

\section{Forensic Factors}

That conviction rates are a poor marker for the size of the problem behaviour in intellectual disability services is well known to practising clinicians. This study indicates this effect extends to those with ASD within such services. For all offence types, e.g. violence, sexual or arson, solely focusing on convictions appears to undercount the numbers by a factor of at least three. This may be due to carers of those with ASD being less likely to involve the police when an offence is committed 
(Lyall et al. 1995; Clare, \& Murphy 1998). Further, the police or crown prosecution service may not deem prosecuting those with ASD who commit offences to be in the public interest. This highlights the need for careful history taking that thoroughly investigates past behaviour, (whether labelled as challenging or offending) and uses that information to plan treatment.

Those with ASD were less likely to be subject to criminal sections or restriction orders than other patients. This suggests that even if offending behaviour is reported and taken forward, those with ASD were treated less harshly by the criminal justice system. This contrasts with Archer and Hurley (2013), who noted that defendants with ASD may be sentenced more punitively. The reasons for this contrast are unclear. It may reflect the picture in one service and would be worth exploring in larger samples.

\section{Clinical Factors and Treatment Outcomes}

Only six women had a diagnosis of ASD. This is in keeping with previous findings (e.g. Dein, \& Woodbury-Smith 2010), but also reflective of the gender composition of the study service.

Those with ASD had a wide range of co-morbidity. Epilepsy was relatively prevalent. Substance abuse was present in a minority of patients, while schizophrenia and personality disorder were more prevalent. These findings somewhat contrast with those reported by Haw et al. (2013) who found high levels of schizophrenia, but low levels of personality disorder. Such comorbidity is likely to significantly impact the approach to treatment. Indeed, the symptoms of schizophrenia are likely to require stabilisation before the individual could proceed with further psychological treatments. Likewise, this range of co-morbidity will require careful consideration 


\section{ASD IN FORENSIC INTELLECTUAL DISABILITY}

when assessing risk in this population, separate from the inherent features of ASD

(Palermo 2004; Murphy 2003; Newman \& Ghaziuddin 2008).

The majority of those with ASD had histories of self-harm. This was significantly higher than those without ASD. Research focusing on self-harm in forensic intellectual disability populations is relatively scarce (Brown \& Beail, 2009), however, this is not an isolated finding. Rojahn et al. (2010) compared those with intellectual disabilities, with and without comorbid ASD on a range of measures, and found those with intellectual disability and ASD demonstrated higher levels of selfinjurious behaviour. This finding indicates the need for careful treatment plans to address self-harm in patients with ASD within forensic services.

Despite the wealth of clinical interest in this area, research describing interventions and their outcomes for offenders with ASD is scarce (Murphy et al. 2007). Three major reports on autism and offending behaviour provide little emphasis on treatment ( National Autistic Society, 2011; Birmingham City Council, 2011; Scottish Executive Social Research, 2004). A number of treatment approaches for individuals with ASD within forensic settings have recently been described. These include individual case treatments (Kelbrick \& Radley, 2013), the ten-point treatment programme (Alexander et al. 2011) and psychological treatments, such as the adapted version of the Equipping Youth to Help One Another Programme (EQUIP; Gibbs et al. 1995; Langdon 2013). Most of these interventions incorporate the core principles of the SPELL approach (National Autistic Society 2013b).

On treatment outcomes, Hare et al. (1999) reported those with ASD in high secure care had significantly longer lengths of stay than those without, though the patients in this study did not have an intellectual disability. In our study, although the ASD group differed from those without on certain clinical and forensic 
characteristics, there were no significant differences on treatment outcomes, defined by length of stay, and direction of care pathway. The ASD diagnosis alone may therefore be inadequate in predicting treatment outcomes. There is a case to identify distinct typologies within the ASD group that may help to better delineate variations within this diagnostic group. This will better inform the most useful interventions for the different subtypes. This requires further examination in a larger, multicentre sample. 
ASD IN FORENSIC INTELLECTUAL DISABILITY

Tables

Table 1: Comparison between those with ASD and those without: Clinical variables

\begin{tabular}{|c|c|c|c|c|}
\hline Examined measure & ASD diagnosis & $\begin{array}{l}\text { No ASD } \\
\text { diagnosis }\end{array}$ & $\begin{array}{c}\text { Statistical } \\
\text { test }\end{array}$ & CI 95\% (OR) \\
\hline Number of patients - 138 & $42(30 \%)$ & $96(70 \%)$ & $\mathrm{n} / \mathrm{a}$ & \\
\hline $\begin{array}{l}\text { Age on admission } \\
\text { (Median, Mean, s.d.) }\end{array}$ & $31,30.14(9.14)$ & $29,30.56(9.38)$ & n.s. & $\mathrm{n} / \mathrm{a}$ \\
\hline $\begin{array}{l}\text { Gender } \\
\text { Male } \\
\text { Female }\end{array}$ & $\begin{array}{c}36(86 \%) \\
6(14 \%)\end{array}$ & $\begin{array}{l}73(76 \%) \\
23(24 \%)\end{array}$ & $\begin{array}{l}\text { n.s. } \\
\text { n.s. }\end{array}$ & $\begin{array}{l}\mathrm{n} / \mathrm{a} \\
\mathrm{n} / \mathrm{a}\end{array}$ \\
\hline $\begin{array}{l}\text { Past experience of abuse } \\
\text { Any abuse } \\
\text { Any sexual abuse }\end{array}$ & $\begin{array}{l}17(40.5 \%) \\
14(33.3 \%)\end{array}$ & $\begin{array}{l}51(53.1 \%) \\
41(42.7 \%)\end{array}$ & $\begin{array}{l}\text { n.s. } \\
\text { n.s. }\end{array}$ & $\begin{array}{l}\mathrm{n} / \mathrm{a} \\
\mathrm{n} / \mathrm{a}\end{array}$ \\
\hline Self-harm & $41(97.6 \%)$ & $70(72.9 \%)$ & .001 & $2-116.4(15.3)$ \\
\hline $\begin{array}{l}\text { Diagnostic comorbidity } \\
\text { Psychosis } \\
\text { Bipolar disorders } \\
\text { Depressive disorders } \\
\text { Harmful use or dependence on } \\
\text { substances } \\
\text { PD (Flamboyant cluster) } \\
\text { PD (Dissocial) } \\
\text { PD (Emotionally Unstable) } \\
\text { Epilepsy }\end{array}$ & $\begin{array}{c}6(14.3 \%) \\
4(9.5 \%) \\
3(7.1 \%) \\
5(11.9 \%) \\
15(35.7 \%) \\
14(33.3 \%) \\
6(14.3 \%) \\
11(26.2 \%)\end{array}$ & $\begin{array}{l}21(21.9 \%) \\
11(11.5 \%) \\
19(19.8 \%) \\
34(35.4 \%) \\
62(64.6 \%) \\
54(56.3 \%) \\
32(33.3 \%) \\
10(10.4 \%)\end{array}$ & $\begin{array}{l}\text { n.s. } \\
\text { n.s. } \\
\text { n.s. } \\
.004 \\
\\
.003 \\
.016 \\
.023 \\
\text { n.s. }\end{array}$ & $\begin{array}{c}\mathrm{n} / \mathrm{a} \\
\mathrm{n} / \mathrm{a} \\
\mathrm{n} / \mathrm{a} \\
0.09-0.7(0.3) \\
0.1-0.7(0.3) \\
0.2-0.8(0.4) \\
0.1-0.9(0.3) \\
\mathrm{n} / \mathrm{a}\end{array}$ \\
\hline
\end{tabular}




\section{ASD IN FORENSIC INTELLECTUAL DISABILITY}

Table 2: Comparison between those with ASD and those without: Forensic variables

\begin{tabular}{|l|c|c|c|c|}
\hline \multicolumn{1}{|c|}{ Examined measure } & $\begin{array}{c}\text { ASD } \\
\text { diagnosis }\end{array}$ & $\begin{array}{c}\text { No ASD } \\
\text { diagnosis }\end{array}$ & $\begin{array}{c}\text { Statistical } \\
\text { test }\end{array}$ & CI 95\% OR \\
\hline Number of patients - 138 & $42(30 \%)$ & $96(70 \%)$ & $\mathrm{n} / \mathrm{a}$ & \\
\hline $\begin{array}{l}\text { Legal status on admission } \\
\text { Detentions under 'criminal' sections }\end{array}$ & $11(26.2 \%)$ & $43(44.8 \%)$ & $\mathrm{n} . \mathrm{s}$. & $\mathrm{n} / \mathrm{a}$ \\
Detentions with a restriction order & $2(4.8 \%)$ & $23(24 \%)$ & $\mathbf{. 0 0 7}$ & $0-0.7(0.2)$ \\
\hline History of convictions & $13(30.1 \%)$ & $50(52.1 \%)$ & $\mathrm{n} . \mathrm{s}$. & $\mathrm{n} / \mathrm{a}$ \\
Conviction for violent offences & $5(11.9 \%)$ & $36(37.5 \%)$ & $\mathrm{n} . \mathrm{s}$. & $\mathrm{n} / \mathrm{a}$ \\
Conviction for sex offences & $2(4.8 \%)$ & $12(12.5 \%)$ & $\mathrm{n} . \mathrm{s}$. & $\mathrm{n} / \mathrm{a}$ \\
Conviction for arson & & & & \\
\hline History of aggression & $42(100 \%)$ & $88(91.7 \%)$ & $\mathrm{n} . \mathrm{s}$. & $\mathrm{n} / \mathrm{a}$ \\
Verbal aggression & $39(92.9 \%)$ & $86(89.6 \%)$ & $\mathrm{n} . \mathrm{s}$. & $\mathrm{n} / \mathrm{a}$ \\
Aggression towards people & $40(95.2 \%)$ & $83(86.5 \%)$ & $\mathrm{n} . \mathrm{s}$. & $\mathrm{n} / \mathrm{a}$ \\
Aggression towards property & $17(40.5 \%)$ & $25(26 \%)$ & $\mathrm{n} . \mathrm{s}$. & $\mathrm{n} / \mathrm{a}$ \\
History of sexual aggression & $6(14 \%)$ & $24(25 \%)$ & $\mathrm{n} . \mathrm{s}$. & $\mathrm{n} / \mathrm{a}$ \\
History of fire setting & & & & \\
\hline
\end{tabular}




\section{ASD IN FORENSIC INTELLECTUAL DISABILITY}

Table 3: Comparison between those with ASD and those without: Treatment Outcome variables

\begin{tabular}{|c|c|c|c|}
\hline Examined measure & $\begin{array}{c}\text { ASD } \\
\text { diagnosis }\end{array}$ & $\begin{array}{l}\text { No ASD } \\
\text { diagnosis }\end{array}$ & $\begin{array}{c}\text { Statistical } \\
\text { test }\end{array}$ \\
\hline \multicolumn{4}{|l|}{ Institutional aggression* - mean (SD) } \\
\hline Number of patients - 114 & 36 & 78 & \\
\hline Physical Intervention & $3.86(8.24)$ & $1.82(4.04)$ & .016 \\
\hline Seclusion & $1.29(1.97)$ & $74(1.98)$ & n.s. \\
\hline Observation & $6.62(7.68)$ & $2.76(4.37)$ & .000 \\
\hline Pro re nata medication (PRN) & $5.11(6.43)$ & $3.92(5.41)$ & n.s. \\
\hline \multicolumn{4}{|l|}{ Length of Stay - (mean, median, (s.d.)) } \\
\hline Discharged - Number of patients - 77 & $\begin{array}{c}28(66.6 \%) \\
1323.7,925,(1101.8)\end{array}$ & $\begin{array}{c}49(51 \%) \\
1372.08,1080.0,(983.2)\end{array}$ & n.s. \\
\hline Not yet discharged - Number of patients - 61 & $\begin{array}{c}14(33.3 \%) \\
1524,1052.0,(1570)\end{array}$ & $\begin{array}{c}47(49 \%) \\
1781,1323.0,(1505)\end{array}$ & n.s. \\
\hline $\begin{array}{l}\text { Outcomes for Discharged Patients - } \\
\text { Number of patients - } 78\end{array}$ & 28 & 49 & \\
\hline \multicolumn{4}{|l|}{ Direction of Care Pathway } \\
\hline Care pathway: good outcome & $24(86 \%)$ & $43(88 \%)$ & n.s \\
\hline Care pathway: poor outcome & $4(14 \%)$ & $6(12 \%)$ & n.s \\
\hline \multicolumn{4}{|l|}{ Discharge Placement $\dagger$} \\
\hline Community- informal & $3(10.7 \%)$ & $10(20.4 \%)$ & n.s \\
\hline Community- guardianship & $3(10.7 \%)$ & $3(6.1 \%)$ & n.s. \\
\hline Community- supervised discharge & $3(10.7 \%)$ & $2(4 \%)$ & n.s. \\
\hline Hospital section & $15(53.4 \%)$ & $28(57.1 \%)$ & n.s. \\
\hline
\end{tabular}

* The total number of each intervention was divided by the total number of months of inpatient stay for each patient and an average monthly intervention figure was generated. 


\section{References}

Alexander R. T., Crouch K., Halstead S. \& Piachaud J. (2006). Long-term outcome from a medium secure service for people with intellectual disability. Journal of Intellectual Disability Research, 50, 305-315.

Alexander R. T., Green F. N., O’Mahony B., Gunaratna I. J., Gangadharan S. K. \& Hoare, S. (2010). Personality disorders in offenders with intellectual disability: a comparison of clinical, forensic and outcome variables and implications for service provision. Journal of Intellectual Disability Research, 54, 650-658.

Alexander R. T., Hiremath A., Chester V., Green F. N., Gunaratna I. J. \& Hoare, S. (2011). Evaluation of treatment outcomes from a medium secure unit for people with intellectual disability. Advances in Mental Health and Intellectual Disabilities, 5, 22-32.

Allen D., Evans C., Hider, A., Hawkins S., Peckett H. \& Morgan H. (2008). Offending Behaviour in Adults with Asperger Syndrome. Journal of Autism and Developmental Disorders, 38, 748-758.

American Psychiatric Association. (2013). Diagnostic and statistical manual of mental disorders (5th ed.). Arlington, VA: American Psychiatric Publishing.

Archer N. \& Hurley, E A (2013). A justice system failing the autistic community. Journal of Intellectual Disabilities and Offending Behaviour, 4, 53-59.

Baron-Cohen S. (1988). An assessment of violence in a young man with Asperger's Syndrome. Journal of Child Psychology and Psychiatry, 29, 351-360.

Birmingham City Council (2011). Adults with autism and the criminal justice system: A report from Overview \& Scrutiny. Author.

Brown J. \& Beail N. (2009). Self-Harm Among People with Intellectual Disabilities Living in Secure Service Provision: A Qualitative Exploration. Journal of Applied Research in Intellectual Disabilities, 22, 503-513.

Butwell, M., Jamieson, E., Leese, M. \& Taylor, P.J. (2000). Trends in special (highsecurity) hospitals. British Journal of Psychiatry, 176, 260-265.

Chen P., Chen S., Yang Y., Yeh T., Chen C. \& Lo H. (2003). Asperger's disorder: a case report of repeated stealing and the collecting behaviours of an adolescent patient. Acta Psychiatrica Scandinavica, 107, 73-76.

Chesterman P. \& Rutter S. (1993). Case report: Asperger's syndrome and sexual offending. Journal of Forensic Psychiatry, 4, 555-562.

Clare I. \& Murphy G. (1998). Working with Offenders or Alleged Offenders with Learning disabilities, In E Emerson, C Hatton, J Bromley, \& A Caine, 


\section{ASD IN FORENSIC INTELLECTUAL DISABILITY}

Clinical Psychology and People with Intellectual Disabilities. Chichester: John Wiley and Sons.

Cooper S., Mohamed W. \& Collacott R. (1993). Possible Asperger's syndrome in a mentally handicapped transvestite offender. Journal of Intellectual Disability Research, 37, 189-194.

Crocombe J., Mills R., Wing L., et al. (2006). Autism Spectrum Disorders in the High Security Hospitals of the United Kingdom. A Summary of Two Studies. The National Autistic Society.

Dein K. \& Woodbury-Smith M. (2010). Asperger syndrome and criminal behaviour. Advances in psychiatric treatment, 16, 37-44.

Everall I. P. \& Le Couter A. (1990). Firesetting in an adolescent boy with Asperger's syndrome. British Journal of Psychiatry, 157, 284-287.

Gibbs J. C., Potter G. \& Goldstein A. P. (1995). The EQUIP Programme: Teaching Youth to Think and Act Responsibly Through a Peer-Helping Approach. Research Press, Champaign, IL.

Gómez de la Cuesta G. (2010). A selective review of offending behaviour in individuals with autism spectrum disorders. Journal of Learning Disabilities and Offending Behaviour, 1, 47-58.

Gunasekaran S. (2012) Assessment and management of risk in autism. Advances in Mental Health and Intellectual Disabilities, 6(6) 314-320.

Hare D. J., Gould J., Mills R., \& Wing L. (1999). A preliminary study of individuals with autistic spectrum disorders in three special hospitals in England. National Autistic Society. Available from: http://www.autism.org.uk/ /media/F6C03DB687454477AF51EC0285B1120 $\underline{9 . a s h x}$

Haw C., Radley J., \& Cooke L. (2013). Characteristics of male autistic spectrum patients in low security: are they different from non-autistic low secure patients? Journal of Intellectual Disabilities and Offending Behaviour, 4, 2432 .

Horovitz M., Matson J. L., Hattier M. A., Tureck K. \& Bamburg J. W. (2013). Challenging Behaviors in Adults With Intellectual Disability: The Effects of Race and Autism Spectrum Disorders. Journal of Mental Health Research in Intellectual Disabilities, 6, 1-13.

Howlin P. (1997). Autism and Asperger syndrome: Preparing for adulthood (2 ${ }^{\text {nd }}$ ed). New York: Routledge.

Kelbrick M. \& Radley J. (2013) Forensic rehabilitation in Asperger syndrome: a case report. Journal of Intellectual Disabilities and Offending Behaviour, 4, 6064. 


\section{ASD IN FORENSIC INTELLECTUAL DISABILITY}

Langdon P E., Murphy G. H., Clare I. C. H, Palmer E. J. \& Rees J. (2013). An Evaluation of the EQUIP Treatment Programme with Men who have Intellectual or Other Developmental Disabilities. Journal of Applied Research in Intellectual Disabilities, 26, 167-180.

Lyall I., Holland A. \& Collins S. (1995). Offending by Adults with Learning Disabilities and the Attitudes of Staff to Offending Behaviour: Implications for service development, Journal of Intellectual Disability Research, 30, 501-508.

Mawson D., Grounds A. \& Tantam D. (1985). Violence and Asperger's Syndrome: A Case Study. British Journal of Psychiatry, 147, 566-569.

Mayor J., Bhate M., Firth H., Graham A., Knox P. \& Tyrer S. (1990). Facilities for Mentally Impaired Patients: Three years experience of a semi-secure unit. Psychiatric Bulletin, 14, 333-335.

Milton J., Duggan C., Latham A., Egan V. \& Tantam D. (2002). Case history of comorbid Asperger's syndrome and paraphilic behaviour. Medical Science and the Law, 42, 237-244.

Murphy G. \& Fernando S. (1999). Services for People with Challenging Behaviour and Mental Health Needs at Risk of Offending. Tizard Learning Disability Review, 4, 31-39.

Murphy D. (2003). Admission and cognitive details of male patients diagnosed with Asperger's Syndrome detained in a Special Hospital: comparison with a schizophrenia and personality disorder sample. Journal of Forensic Psychiatry and Psychology, 14, 506-24.

Murphy D. (2007). Hare Psychopathy Checklist Revised profiles of male patients with Asperger's syndrome detained in high security psychiatric care. Journal of Forensic Psychiatry and Psychology, 18, 20-126.

Murrie, D. C., Warren, J. I., Kristiansson, M. \& Dietz, P. E. (2002). Asperger's Syndrome in Forensic Settings. International Journal of Forensic Mental Health, 1, 59-70.

National Autistic Society (2011). Autism: a guide for criminal justice professionals. London, Author.

National Autistic Society (2013). Autism and Asperger syndrome: some facts and statistics. Available from: http://www.autism.org.uk/about-autism/mythsfacts-and-statistics/some-facts-and-statistics.aspx

National Autistic Society (2013). SPELL. Available from: http://www.autism.org.uk/spell 


\section{ASD IN FORENSIC INTELLECTUAL DISABILITY}

Newman S. S. \& Ghaziuddin M. (2008). Violent Crime in Asperger Syndrome: The Role of Psychiatric Comorbidity. Journal of Autism and Developmental Disorders, 38, 1848-1852.

North A. S., Russell A. J. \& Gudjonsson G. H. (2008). High functioning autism spectrum disorders: an investigation of psychological vulnerabilities during interrogative interview. The Journal of Forensic Psychiatry \& Psychology, 19, 323-334.

Palermo M. T. (2004). Pervasive developmental disorders, psychiatric co-morbidities, and the law. International Journal of Offender Therapy and Comparative Criminology, 48, 40-48.

Rojahn J., Wilkins J., Matson J. R. \& Boisjoli J. (2010). A Comparison of Adults with Intellectual Disabilities with and without ASD on Parallel Measures of Challenging Behaviour: The Behavior Problems Inventory-01 (BPI-01) and Autism Spectrum Disorders-Behavior Problems for Intellectually Disabled Adults (ASD-BPA). Journal of Applied Research in Intellectual Disabilities, 23, 179-185.

Schwartz-Watts, D. M. (2005). Asperger's disorder and murder. Journal of the American Academy of Psychiatry and the Law, 33, 390-393.

Scottish Executive Social Research (2004). On the Borderline? People with Learning Disabilities and/or Autistic Spectrum Disorders in Secure, Forensic and Other Specialist Settings. Edinburgh: Author.

Scragg P. \& Shah A. (1994). Prevalence of Asperger's Syndrome in a Secure Hospital. The British Journal of Psychiatry, 165, 679-682.

Silva A., Ferrari M. \& Leong G. (2002). The case of Jeffrey Dahmer: sexual serial homicide from a neuropsychiatric developmental perspective. Journal of Forensic Sciences, 47, 1347-1359.

Siponmaa L., Kristiansson M., Jonson C., Nydén A. \& Gillberg C. (2001). Juvenile and young adult mentally disordered offenders: the role of child neuropsychiatric disorders. Journal of American Academy of Psychiatry and the Law, 29, 420-6.

Wing L. (1997). Asperger's syndrome: management requires diagnosis. Journal of Forensic Psychiatry; 8, 253-7.

Wing L. \& Gould J. (1979). Severe impairments of social interaction and associated abnormalities in children. Epidemiology and classification. Journal of Autism and Developmental Disorders, 9, 11-29.

Woodbury-Smith M. R., Clare I.C.H., Holland A.J. \& Kearns A. (2006). High functioning autistic spectrum disorders, offending and other law-breaking: findings from a community sample. The Journal of Forensic Psychiatry \& Psychology, 17, 108-120. 
ASD IN FORENSIC INTELLECTUAL DISABILITY

Woodbury-Smith M. R. \& Volkmar F. R. (2008). Asperger Syndrome: a review. European Journal of Child and Adolescent Psychiatry; 56, 1-11.

Woodbury-Smith M. R., Clare I., Holland A., Kearns A., Staufenberg E. \& Watson P. (2005). A case-control study of offenders with high functioning autistic spectrum disorders. The Journal of Forensic Psychiatry \& Psychology, 16, 747-763. 